\title{
Varying Instructional Approaches to Physical Extraction of Mobile Device Memory
}

Joan Runs Through

runsthrough@dixie.edu

Gary D. Cantrell

Dixie State University, cantrellg@gmail.com

Follow this and additional works at: https://commons.erau.edu/jdfsl

Part of the Computer Law Commons, Higher Education Commons, Information Security Commons, and the Other Computer Sciences Commons

\section{Recommended Citation}

Runs Through, Joan and Cantrell, Gary D. (2017) "Varying Instructional Approaches to Physical Extraction of Mobile Device Memory," Journal of Digital Forensics, Security and Law. Vol. 12 : No. 4 , Article 4.

DOI: https://doi.org/10.15394/jdfsl.2017.1420

Available at: https://commons.erau.edu/jdfsl/vol12/iss4/4

This Article is brought to you for free and open access by

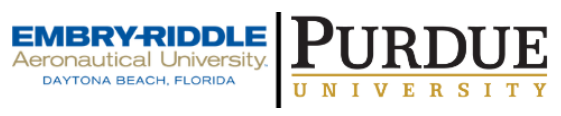
the Journals at Scholarly Commons. It has been accepted for inclusion in Journal of Digital Forensics, Security and Law by an authorized administrator of Scholarly Commons. For more information, please contact commons@erau.edu.

(c)ADFSL 


\title{
VARYING INSTRUCTIONAL APPROACHES TO PHYSICAL EXTRACTION OF MOBILE DEVICE MEMORY
}

\author{
Joan Runs Through \\ Assistant Director DSU-CCI \\ 225 South 700 East \\ St. George, UT 84770 \\ 435.879 .4420 \\ runsthrough@dixie.edu \\ Gary Cantrell \\ Associate Professor of Digital Forensics \\ 225 South 700 East \\ St. George, UT 84770 \\ 435.879 .4422 \\ cantrell@dixie.edu
}

\begin{abstract}
Digital forensics is a multidisciplinary field encompassing both computer science and criminal justice. This action research compared the demonstrated skill levels of students enrolled in a semester course in small device forensics with an 18-hour unit on NAND memory chip extraction and analysis (chipoff forensics) against the skill levels of industry professionals after completing a 40-hour workshop on chip-off forensics. Participant backgrounds were also examined to determine if those students with a background in computer science had an advantage over students with a criminal justice background. Study participants were volunteers ranging in age from 20 to over 60 and had a variety of backgrounds and prior work experience. Volunteers completed a timed trial comprised of four timed subtasks. Results were compared for both quality and speed in task. Qualitative, quantitative, and observational data were gathered throughout the course of this study. Data was analyzed through the use of graphs and tables.
\end{abstract}

Keywords: digital forensics, digital forensics education, small device forensics, chip-off extraction

\section{INTRODUCTION}

Digital forensics is a relatively new field in academia. As collegiate computer forensics courses emerge and develop, it is important that the institutes of higher learning evaluate these courses and the procedures taught therein. The field of digital forensics has developed standards for the handling and processing of artifacts residing in computer file systems and operating systems. The sub discipline of small devices or mobile forensics, however, has not yet settled into a standard format. New models of cell phones and tablets are released onto the market monthly. Each new model often stores data in a new and proprietary manner, frustrating the automated forensic tools designed to extract 
said data (Casey, Bann, \& Doyle, 2010). Other obstacles to small device forensics includes security locks, damaged devices, damaged/disabled data ports, and encryption.

Solutions to small device forensics include automated and manual processes (McCarthy, 2005). Automated processes include forensic software suites that simply require an examiner to connect a device and press a button, thereby earning the term, "push-button forensics," These suites are rarely customizable and require little interaction between the end user and the end results. The use of such equipment is the focus of many small device forensic certification courses.

Cell phone and other personal electronic devices utilize a wide variety of file systems, operating systems, and artifact formats. At present, cell phones are typically examined live (Al-Zarouni, 2006). Forensic software suites require a cell phone to be booted in order for forensic software to extract data. The software sends commands to the device and the operating system on the device responds by sending data to the forensic workstation. Each model of phone must be individually programmed into each software suite; thus, these software suites support a limited percentage of consumer devices. In addition, data extracted from the cell phone is limited to data to which the phone's operating system permits access. A need exists for processes that will allow forensic examination of problem cell phones and personal electronics (McCarthy, 2005). Chip-off forensics bypasses the cell phone's operating system and copies all data bit for bit post mortem.

The resulting bit-for-bit image needs to be parsed for evidentiary data. This can be done using automated tools, or the examiner may do this manually. When done manually (without pre-packaged, automated tools), the examiner must display a higher skill level to identify and extract data. Due to this, manual parsing can be time intensive.

The goal of this study is to evaluate the 54 hours of a semester course in small device forensics with a physical extraction emphasis. The resulting skill levels of a sampling of students in this course will then be compared to the resulting skill levels of forensic professionals having completed an accelerated 40-hour training covering similar materials. Chip-off forensics is a unique skill to teach in an undergraduate setting.

Interest in the chip-off process is high among forensic examiners whose automated forensic tools are not meeting their needs. Phones not supported by automated tools include patternlocked Androids, password protected Blackberries, as well as TracFones and other pay-as-you-go phones with provider disabled data-ports (Hoog, 2011). These last phones are so prevalent with those who commit crimes that they are known as "burner phones" by law enforcement, indicating they are disposable phones purchased with the sole purpose of aiding in crime.

It is interesting to note the subject university's approach to digital forensics; many colleges/universities in the United States teach computer forensics in association with a Computer Science or Information Technology department. The subject university teaches its computer forensics emphasis as part of a criminal justice bachelor's degree (digital forensics emphasis). Students from the Computer Science and IT departments are invited and encouraged to take digital forensic courses as electives, and also have the option of adding the digital forensic minor to their technical degree, but the overall viewpoint expressed is that of criminal justice over computer science.

From time to time, this sparks debate as to who is better prepared coming into the program. 
Thus, also reviewed in this action research will be the overall performance of students with a criminal justice background as compared to those with an IT or computer science background. The analysis of a binary image or hex dump is analysis at such a low level (meaning the data is close to the machine language and far from the human readable user interface) that it is not taught in the general instruction of computer science or information technology. Therefore, concern is expressed regarding prior levels of technological proficiency needed for students to develop proficiency in low level analysis at the undergraduate level.

\section{THE PROBLEM}

New students are quick to jump on the bandwagon of each new technique but can become easily overwhelmed when results require more than pushing the next button on a forensic solution software suite. Older professionals struggle to believe the more advanced techniques are possible outside of the national FBI lab or a well-funded research facility, and therefore discuss such techniques as one would an urban legend. This is particularly noticeable in the technique known as chip-off forensics. In chip-off, a small ball grid array (BGA) flash memory chip is removed from the printed circuit board (PCB). The chip is placed in a reader, which allows for a computer to extract a bit-forbit copy of the binary information contained on the chip. The binary dump is then examined, researched and parsed for text messages, pictures, contacts, and other user-inputted data (Hoog, 2011).

A need exists for more examiners, more and better-funded laboratories and more advanced techniques (Houck, 2006). Law enforcement agents report that backlogs at the FBI sponsored Regional Computer Forensic Labs cause waiting lists lasting six to twelve months (Matthews, 2013).
Far worse than the backlog existing in digital forensic laboratories, is the inability of these laboratories to process specific items of evidence. The chip-off process, long maligned in the United States as being expensive and time consuming, requires another look if only because of the example set by the Netherlands and England. Students and law enforcement professionals trained in this technique become an asset to the workforce. Further research into streamlining the technique and developing more cost-effective equipment is also warranted. Students equipped with a practical working knowledge of these techniques are also prepared to research and create needed equipment and processes.

\section{RESEARCH METHODOLOGY}

Both qualitative and quantitative methods were used in this study. Qualitative methods included an observation journal and student questionnaires including objective questions and questions with a Likert Scale type rating. Quantitative methods included evaluations of mock case analysis, timed tasks as well as end of term grades. The use of multiple data collection tools was implemented in an effort to paint a clearer picture of the efficacy of the chipoff training, and the prior knowledge recommended to successfully acquire this skill. The two primary research questions were:

1. Do students with a computer science/IT background have a higher success rate than criminal justice majors when learning the chip off process?

2. Do students in the 40-hour intensive training workshops have a higher success rate when learning the chip-off procedure than those who complete an 18-hour chip-off unit in a 3-credit semester course in small device forensics? 


\section{HYPOTHESES}

Students completing 54 hours in mobile forensic physical processes throughout a three-credit hour semester course in small device forensics will have skill levels within a $10 \%$ variance of industry professionals trained on similar materials through a 40-hour workshop as determined by time completion and scoring of a chip-off trial. Participants with a computer science/IT background have a technical advantage and will therefore attain a $20 \%$ or higher performance level than those participants with criminal justice/non-technical backgrounds as determined by time completion time and scoring of a chip-off trial.

\section{RESEARCH DESIGN}

This study was a mixed method action research designed to assess differences in skill levels attained through a unit in a traditional on campus course versus an intensive 40-hour workshop. Both quantitative and qualitative data were collected to assess not only each participant adeptness at the skill at hand, but to gather information regarding attitudes and self-confidence regarding the task in question.

Participants were members of two separate cohorts, a workshop cohort and a campus cohort. The workshop cohort was comprised of five students, all with law enforcement experience. Four of the workshop participants were male, and one was female. Three of the five students in the workshop cohort had bachelor's degrees prior to chip-off training.

The campus cohort was comprised of four undergraduate students enrolled in the criminal justice bachelor's degree program with a digital forensics emphasis or in the computer science bachelor's degree program. Two of the four students in the campus cohort had earned bachelor's degrees prior to chip-off training. Three of the campus participants were male, and one was female.

\section{EVALUATION METHODS AND TOOLS}

Each participant was given a factory reset (blank) Samsung SCH-U450 cell phone. Participants were asked to enter text messages and contacts into the phone. They were also asked to use the phone to snap random photographs. With known content added to the phones, participants were prepared to begin the chip-off process. Participants were timed as they completed the following sub-tasks:

1. Remove the BGA chip from the PCB (de-solder)

2. Place chip in reader/programmer and successfully read (extract binary image)

3. Carve SMS/Pictures/Contacts (Participant choice of Scalpel, FTK Imager, and/or Cellebrite Physical Analyzer. Most student used a combination of the three.)

4. Create a 2-page minimal report that documented three SMS, three contacts, and five pictures.

Research data was gathered from the following six different sources:

- Qualitative Data: This data included first-hand observation of the researcher and feedback from students.

- Observation Journal: The researcher completed a journal entry after each instructional unit/classroom unit. Questions asked by students, anecdotal remarks on common or uncommon errors, failed tasks, and frustration level of students were noted in journal entries.

- Student Questionnaire: Prior to instruction, students were asked to complete a student questionnaire detailing prior experience, computer training, level of education, age, sex, 
race, interest in the field of digital forensics, and expectations of the course.

- Student Completion Survey: Postinstruction, students with employment in a forensic lab setting were asked to complete a Likert Scale survey asking them to rate their training, their perceived level of expertise, and their opportunity to utilize their training. Anecdotal information was also requested.

\section{- Mock Case Analysis :}

Participating students were asked to work a mock case. Students received points for successfully removing a BGA chip from a PCB board, inserting the BGA chip into a programmer/reader, extracting a viable binary image, and effectively translating data within a binary image into a human readable form appropriate for the court system. In addition, students recorded the amount of time required for each task.

- End-of-Term Grades: Students in the Campus Course received an end-of-term grade. These grades were compared to student responses on the Student Questionnaire and analyzed for notable differences between students with a criminal justice background and students with a computer science background.

The mock case was a timed performance assessment that returned qualitative data. In theory, a shorter performance time indicated confidence in and understanding of the acquired chip-off skills. The performance assessment was subdivided into four separate tasks. Each task was graded as pass/fail. The number of successfully completed tasks was compared to student demographic information as well as cohort to produce a percentage of each cohort/demographic who successfully complete each task.

\section{RELIABWITY AND VALDITY.}

Chip-off forensics is a relatively new field and as such, only a small pool of qualified participants exists. Timed trials were included in this study as a way to ensure repeatability. Course materials were beta tested in Thailand with participants from the Royal Thai Police and the Thai Electronic Transaction Development Agency. Beta testing students included those with criminal justice backgrounds and those with computer science backgrounds. Feedback was given regarding course materials and individual tasks.

Course material was reviewed by two subject matter experts for accuracy and task appropriateness. Subject matter experts used the course materials to conduct training for two workshops and one on campus course before testing was approved. Course material adjusted according to feedback from the subject matter experts included changing the sequence material was presented.

While the subject cohorts matched somewhat in education and gender, no attempt was made to choose participants. Participants included one complete class of Chip-Off Forensic Training enrollees with law enforcement backgrounds and random volunteers from an undergraduate semester course in small device forensics.

\section{DATA DRIVEN FINDING SUMMARY}

The data gathered did not fully support the hypothesis. The resulting points from the chipoff timed trial displayed a significant difference (25\%) between the campus cohort and the workshop cohort (Table 1 and Table 2). In addition, the workshop cohort reached 100\% completion of all tasks, whereas only two of the four students (50\%) in the campus cohort 
successfully completed all tasks. One student was unable to retrieve photographs, while another student's chip was damaged in the chipoff process and therefore no data was extracted.

Table 1

Campus Cohort Timed Trial Results

\begin{tabular}{llllll}
\hline Remove BGA & Extract Binary & Carve Data & Create Report & Total Time & Points \\
$12 \mathrm{~min}$ & $09 \mathrm{~min}$ & $106 \mathrm{~min}$ & $19 \mathrm{~min}$ & $125 \mathrm{~min}$ & 50 \\
$12 \mathrm{~min}$ & $22 \mathrm{~min}$ & $145 \mathrm{~min}$ & $34 \mathrm{~min}$ & $179 \mathrm{~min}$ & 40 \\
$22 \mathrm{~min}$ & $10 \mathrm{~min}$ & $104 \mathrm{~min}$ & $24 \mathrm{~min}$ & $128 \mathrm{~min}$ & 50 \\
$10 \mathrm{~min}$ & $\mathrm{n} / \mathrm{a}$ & n/a & n/a & 180 & 10 \\
\hline
\end{tabular}

Times of students are listed in no particular order

Table 2

Workshop Cohort Timed Trial Results

\begin{tabular}{|c|c|c|c|c|c|}
\hline Remove BGA & Extract Binary & Carve Data & Create Report & Total Time & Points \\
\hline $01 \mathrm{~min}$ & $01 \mathrm{~min}$ & $50 \mathrm{~min}$ & $10 \mathrm{~min}$ & $62 \mathrm{~min}$ & 50 \\
\hline $04 \mathrm{~min}$ & $20 \mathrm{~min}$ & $100 \mathrm{~min}$ & $16 \mathrm{~min}$ & $150 \mathrm{~min}$ & 50 \\
\hline $03 \mathrm{~min}$ & $09 \mathrm{~min}$ & $88 \mathrm{~min}$ & $20 \mathrm{~min}$ & $120 \mathrm{~min}$ & 50 \\
\hline $01 \mathrm{~min}$ & $01 \mathrm{~min}$ & $120 \mathrm{~min}$ & $18 \mathrm{~min}$ & $240 \mathrm{~min}$ & 50 \\
\hline $02 \mathrm{~min}$ & $30 \mathrm{~min}$ & $90 \mathrm{~min}$ & $18 \mathrm{~min}$ & $140 \mathrm{~min}$ & 50 \\
\hline
\end{tabular}

Times of students are listed in no particular order

The average time taken to complete the task was nearly $7 \%$ higher for the campus cohort (Table 1 and Table 2). The workshop cohort had a participant who was able to complete the entire task in just over 60 minutes, whereas the campus cohort had one participant who spent three hours trying to unsuccessfully repair a chip. When these two extremes are removed, the campus cohort shows a completion time 11\% faster than that of the workshop cohort. Which lends data to support the research hypothesis. 
Fifty percent of the participants in the campus cohort had IT/computer science backgrounds and $50 \%$ had criminal justice backgrounds. Those with a computer science background performed better than those with a criminal justice background. The IT/computer science students averaged of 45 points as compared to the average of 35 points earned by the criminal justice students or an increase of $22 \%$. The criminal justice students averaged a total time of 154 minutes compared to 152 minutes averaged by the computer science students of an increase of $1 \%$.

No comparisons could be made of the workshop cohort as none of the participants had an original background in computer science or IT. All had received training in digital forensics after pursuing a career in law enforcement. Each had received a bachelor's degree in fields as varied as English, psychology, behavioral science, and biology. Four of the five participants pursued training in computer science after the opportunity to work in digital forensics presented itself.

To enhance the timed trial data gathered regarding background training and its influence on the learning of digital forensics in general and chip-off forensics specifically, a survey was made of the associated small device forensics course in which 18 hours of chip-off training was presented. The class consisted of 18 students, 17 of whom completed the class. Of the 17 completing students, seven identified themselves as IT/computer science majors. The remaining ten students were identified as criminal justice students. The average grade for the computer science students was $87.3 \%$ with a range of $93.2 \%$ to $79.8 \%$. The average grade for the criminal justice students was $86.2 \%$ with a range of $97.6 \%$ to $73.2 \%$.

\section{DATA ANALYSIS}

At individual tasks, the workshop cohort worked at a quicker pace, with the BGA chip removal displaying the greatest variance. The workshop cohort's average removal time was 2.2 minutes with a mean of one minute and a range of one to 4 minutes. The campus cohort's average removal time was 14 minutes with a mean of 12 minutes and a range of 10 to 14 minutes. This represents an $84 \%$ increase in time over the workshop cohort.

It is important to note here that the Samsung SCH-U450 contains a small 138MB NAND Memory chip. This chip, in all cases, was removed by heat not to exceed 480 degrees Fahrenheit. Heat was applied from below with a ceramic plate and from above with high intensity lamp. Data is currently being gathered for additional research on eMMC chips.

The extraction of the binary dump displayed the least degree of variance. The workshop cohort averaged 12.2 minutes at this task, with a range of 1 to 30 minutes. The campus cohort averaged 13.7 minutes at this task, with a range of 9 to 22 . This is based on three trials, as on chip was not successfully read. The percentage of change between the workshop cohort and the campus cohort in this instance is $10 \%$.

A $24 \%$ difference in time was noted between the time required for the workshop cohort to carve evidentiary data and the time required for the campus cohort. The workshop cohort averaged 89.6 minutes with a range of 50 minutes to 120 minutes. The campus cohort averaged 118.3 minutes with a range of 104 to 145 minutes.

A $36 \%$ difference in time was noted between the time required for the workshop cohort to write a report detailing the discovered data and the time required for the campus cohort. The workshop cohort averaged 16.4 minutes with a range of 10 minutes to 20 minutes. The campus cohort average 25.7 minutes with a range of 19 minutes to 34 minutes. 
From this data it is appears that skills developed through professional work in other digital forensic tasks is transferrable to the chipoff forensic process. Teacher observation noted a celebratory tone throughout the workshop cohort's chip-off trial. Participants appeared eager to show off what they had learned. The 40-hour chip-off training provided participants with the opportunity to perform a complete chip-off of three to four phones. While several verbal comments were heard expressing a desire for more hands-on chip-off practice throughout the course, none of the participants expressed this as a response to the post-survey question: What suggestions would you make for improving this course? Responses to this question included:

I would like to see more time on Scalpel and Strings, since many of the phones I deal with are Tracfones

A bit more info on carving options

More time on repairing phones

The following are workshop cohort responses to the question: What did you like about chip-off training?

So much hands on - very limited PowerPoints

Doing the chip-off and repair of phones

Loved the hands on, pulling the chips in /illegible/ and it was great to be able to pull multiple

Workshop cohort participants completed the chip-off task on the last day of the 40-hour training. As it was the final activity, participants were free to leave once the task was complete. This may have contributed to the celebratory mood of the test. Campus cohort participants, on the other hand, scheduled a time to complete the trial. Students worked individually, with only two trials overlapping in time. Teacher journal entries noted signs of both stress and frustration.

Students in the campus cohort had completed one in-class chip-off procedure prior to participating in the timed trial. Many expressed both verbally and in writing the desire for more hands-on training and application. The following are campus cohort responses to the question: What suggestions would you make for improving this course?

More hands-on training, use more time on all tools that are available.

More understanding on what to do, which tool, how to search, etc.

Demonstration of $B G A$ repair

I think the course is great as is

The following are workshop cohort responses to the question: What did you like about chip-off training?

Hands-on! I was able to open up phone and analyze the interior parts

That it is a very unique procedure that not. many people know about

State of the art technology

Data gathered from the Student Completion Survey indicated 13\% difference between confidence felt by those attending the attending the workshop cohort and the campus cohort (Table 3 and Table 4). On a Likert scale, participants rated their confidence on seven areas of small device forensic tasks, including the four tasks of the chip-off trial. After the trial, participants in the workshop cohort averaged a 3.7 on a scale that listed 4 as 'very confident' and 1 as 'extremely unsure.' On the same scale, students in the campus cohort average a 3.2 , indicating 'somewhat confident.' 
Table 3

Student Questionnaire Campus Cohort

\begin{tabular}{|c|c|c|}
\hline Strongly & & \\
\hline Disagree & Disagree & Agr \\
\hline
\end{tabular}

I am comfortable working with computers and technology 4 students

I would like to work with computers and technology in the future

I would like to work in a forensics

field in the future

I am comfortable with my

knowledge of the law and the

4 students

court system

I would like to work in the court

system in the future.

1 student 3 students 
Table 4

Student Questionnaire Workshop Cohort

\begin{tabular}{|c|c|c|c|c|}
\hline & $\begin{array}{l}\text { Strongly } \\
\text { Disagree }\end{array}$ & Disagree & Agree & $\begin{array}{l}\text { Strongly } \\
\text { Agree }\end{array}$ \\
\hline $\begin{array}{l}\text { I am comfortable working with computer } \\
\text { and technology }\end{array}$ & & & 1 student & 4 students \\
\hline $\begin{array}{l}\text { I would like to work with computers and } \\
\text { technology in the future }\end{array}$ & & & & 5 students \\
\hline $\begin{array}{l}\text { I would like to work in a forensics field in } \\
\text { the future }\end{array}$ & & & & 5 students \\
\hline $\begin{array}{l}\text { I am comfortable with my knowledge of } \\
\text { the law and the court system }\end{array}$ & & & & 5 students \\
\hline $\begin{array}{l}\text { I would like to work in the court system } \\
\text { in the future. }\end{array}$ & & 2 students & & 3 students \\
\hline
\end{tabular}

Prior to the training, students indicated their comfort level with computers and with criminal justice topics. All students in the workshop cohort and the campus cohort agreed or strongly agreed that they are comfortable working with computers. Students in both cohorts disagreed with the statement that they like or would like to work with the US court system (Table 3 and Table 4).

\section{ANSWERS TO THE RESEARCH QUESTIONS}

Do students with a computer science/IT background have a higher success rate than criminal justice majors when learning the chip off process?

Success at digital forensics in general and the chip-off process in particular did not appear to be dependent upon knowledge in a specific background field. While in the campus cohort students with a computer science background performed at a slightly higher level $(87.3 \%$ to 86.2 ), the $1.1 \%$ is a minimal distinction. Kessler and Shirling (2006) assert that digital forensics requires skills from both the field of criminal justice and computer science. Data gathered from this study indicates that neither field is more important than the other. Data gathered from the workshop cohort would indicate that skills in digital forensics and chip-off procedures can be learned regardless of preliminary undergraduate studies.

Do students in the 40-hour intensive training workshops have a higher success rate when learning the chip-off procedure than those who complete an 18-hour in a 3 -credit semester course in small device forensics? 
A higher success rate was achieved by students participating in a 40-hour training workshop over students completing the 3 -credit semester course in small device forensics. This in part can be attributed to the additional time for hands-on learning, but in part it should also be noted that participants in the 40-hour training workshop were able to apply skills gained from prior digital forensic experience toward the chip-off procedural tasks.

\section{FINDINGS SUMMARY}

It was hypothesized that students completing the three-credit hour semester course in small device forensics will have skill levels within a $10 \%$ variance of industry professionals trained through a 40-hour workshop in the chip-off procedure as determined by completion time and scoring of a chip-off trial. Participants with a computer science/IT background have a technical advantage and will therefore attain a $20 \%$ or higher performance level than those participants with criminal justice/non-technical backgrounds as determined by time completion time and scoring of a chip-off trial.

Data gathered by this research study indicated that while students in the campus cohort were able to complete the subject trial within a $10 \%$ variance of those in the workshop cohort, the quality of the tasks completed was not within the $10 \%$ variance. Workshop cohort members earned $25 \%$ more points than those in the campus cohort.

Participants with a computer science/IT background did not attain a $20 \%$ or higher performance level than those participants with non-technical backgrounds. No data could be gathered in this area from the chip-off trial. Grade comparisons from the small device forensics semester course indicated a $1.1 \%$ final grade difference between students with a

(C) 2017 ADFSL computer science background and those with a criminal justice background.

\section{IMPLICATIONS}

The assertion has been made that the chip-off process, while effective, is too costly and highly skilled to be a viable solution to data extraction from problem small devices. In this study, both students receiving forty hours of instruction and students receiving eighteen hours of instruction were able to successfully remove a BGA chip from a PCB board, place the BGA chip in a reader/programmer to extract a binary image, parse the image for data, and include the carved data in a suitable report.

The rework station used to remove the chip was a T862 IRDA infrared heating rework station retailing for just over $\$ 300$. While this machine is not as precise as the $\$ 30,000$ German rework station utilized by the university's digital forensics lab, it was able to effectively work on the Samsung SCH-U450's employed by this study. The reader/programmer used for this study was the Up\&Up 818, which retails for under $\$ 1,000$ as does the required A110 adapter. The total cost of equipment used for this trial was just over $\$ 2,000$.

It needs be stated that the T862 IRDA is not recommended for newer phones, as it does not regulate chip temperature. Chips heated to over 350 degrees Celsius risk irreparable damage to data stored on the chip. The university associated with this study is currently in the process of developing a chip-off device with regulatory features that will cost under $\$ 5,000$. The implications of this study demonstrate that the chip-off process is both an affordable process and a skill that can be reasonably acquired.

\section{LIMITATIONS}

The limitations of this study are manifest in the unique nature of the subject matter. As few people in the United States are practicing or studying the process of chip-off forensics, it was 
not possible to perform this study with largeness of population or randomness in selection. In addition, few to no studies have been made regarding this area. Thus, a norm could not be established, nor a comparison made to other work.

In addition, this study was completed with a very small pool of participants. Digital forensics is a relatively new field of university study. The chip-off forensics procedure is a cutting-edge procedure currently only practiced at a handful of labs inside the United States. Studies into effective methods of teaching this procedure were not found. No norm, therefore, could be established, as the body of research into this subject was at the time non-existent.

\section{RECOMMENDATIONS}

Additional research is recommended in the field of digital forensics instruction. Instruction at the primary and secondary level is highly researched. Teachers at the primary and secondary level are trained in pedagogy and instructional practices. Instructors and professors at the college and university level are not required to complete any pedagogy courses and therefore often rely on research done at the secondary level to determine best practices. Fields of study taught solely at a college/university level, therefore, are sometimes lacking in development of pedagogical research and instructional design.

A fear exists that the forensic sciences are fad driven and a result of a CSI Effect, a national sudden interest in the use of science to solve crimes as depicted on highly popular television dramas such as the successful CSI franchise, Bones, Body of Evidence, and Law and Order. The increase of digital forensics programs at the college and university level appears to be driven by a public demand under the influence of the CSI Effect (Mardis, 2006). It is the responsibility of colleges and universities offering digital forensic programs to design instruction that offers subjects and training that include sound scientific techniques and meet the spirit and letter of the law.

\section{FURTHER INVESTIGATION}

While all that could be done to keep the timed trial between cohorts equal, one major difference existed. Students in the campus cohort performed their timed trial individually, while participants in the workshop cohort performed their timed trial as a group. If this study were to be replicated, both groups would be made equal in this area. The recommendation would be for both cohorts to complete the trials as a group. This method appeared to give the better results as it both promoted competition and reduced frustration.

As a method of maintaining anonymity, times for each task were self-reported. Were this study to be repeated, it is recommended that a third-party observer record the times of completion, thereby standardizing the measurement. It is recognized that with selfreporting each participant defines the start point and the end point of the activity. With a single third-party recorder, the start point and end point would be similar across the board.

Further investigation planned for this topic of study includes long-term effects of the chipoff training. Are participants who complete the forty-hour chip-off training workshop able to effectively use the chip-off processes in their workplace? A follow-up with students graduating with an emphasis in digital forensics is also planned. Does post-employment of these students involve careers in the digital forensics field? Do their credits in digital forensics help them obtain employment? Does their knowledge and skill in chip-off forensics make them competitive in the job market? These are questions that will fuel future research investigation. 


\section{REFERENCES}

Al-Zarouni, M. (2007). Introduction to mobile phone flasher devices and considerations for their use in mobile phone forensics. Proceedings of the 5th Australian Digital Forensics Conference, Edith Cowan University, P. Perth Western Australia: Research Online.

Al-Zarouni, M. (2006). Mobile handset forensic evidence: a challenge for law enforcement. 4th Australian Digital Forensics Conference. Perth Western Autralia: Research Online.

Breeuwsma, M., de Johngh, M., Klaver, C., van der Knijff, R., \& Roeloffs, M. (2007). Forensic data recovery from flash memory. Small Scale Digital Device Forensics Journal, 1 (1), 1-17.

Campbell, M. (2012, December 27). Apple Insider. Retrieved December 31, 2012, from appleinsider.com:

http://appleinsider.com/articles/12/12/27/ christmas-2012-17m-ios-and-android-deviceactivated-87-jump-in-app-store-downloads

Cantrell, G. (2012). Creation and resting of a semi-automated digital triage process model. Mississippi State University.

Casey, E., Bann, M., \& Doyle, J. (2010). Introduction to window mobile forensics. Digital Investigation, 6, pp. 136-146.

Elder, R. (2012, May-June). Chip-off and JTAG analysis for mobile device forensics. Evidence Magazine, 10 (3), pp. 10-15.

Garfinkel, S., Farrell, P., Rousseu, F., \& Dinolt, G. (2009). Bringing science to digital forensics with standardized forensic corpora. Digital Investigations, 6 (S), pp. 2-11.

Hoog, A. (2011). Android forensics: investigation, analysis and mobile security for google android. Waltham, MA, USA: Syngress.
Houck, M. (2006). CSI: Reality. Scientific American, 295 (1), 84-89.

Irons, A., Stephens, P., \& Ferguson, R. (2009, April 2). Digital investigation as a distinct discipline: a pedagogic perspective. Digital Investigations, 6, pp. 82-90.

Jonathan Clark. (2000). Forensic Telecommunications Services. Retrieved January 15, 2013, from About FTS: http://www.forensicts.co.uk

Kessler, G., \& Shirling, M. E. (2006). The design of an undergraduate degree program in computer \& digital forensics. Journal of Digital Forensics, Security and Law, 1 (3), 37-50.

Matthews, W. (2013, January 12). Southwest Regional Computer Crime Institute Director. (J. R. Through, Interviewer)

McCarthy, P. (2005). Forensic analysis of mobile phones. University of South Australia, School of Computer and Information Science. Mawson Lakes: University of South Australia.

Muncaster, P. (2013, May 27). The Register. Retrieved June 4, 2013, from www.theregister.com.uk:

http://www.theregister.co.uk/2013/05/27/1 enovo_us_smartphone_launch/

Reisinger, D. (2011, June 28). news.cnet.com. Retrieved December 31, 2012, from cnet.com: http://news.cnet.com/830113506_3-20074956-17/google-500000android-devices-activated-each-day/

Rogers, M. K., \& Seigfried, K. (2004, January $6)$. The future of computer forensics: a needs analysis survey. Computers $\&$ Security, 23, pp. 12-16.

Russell Brewis. (2012). Forensic Telecommunications Services. Retrieved 
January 12, 2012, from forensicts: Wassenaar, D., Woo, D., \& Wu, P. (2009). A http://www.forensicts.co.uk/SubCategory.a spx?ID $=80 \&$ SMID $=103$

Science Daily. (2009, January 1). Retrieved December 31, 2012, from sciencedaily.com: http://www.sciencedaily.com/videos/2009/ 0104-digital_evidence.htm certificate program in computer forensics. Consortium for Computing Sciences in Colleges: Southwestern Conference.24, pp. 158-167. University of Maryland University College Europe. 